\title{
5'-AMP-Activated Protein Kinase Catalytic Subunit Alpha-1
}

National Cancer Institute

\section{Source}

National Cancer Institute. 5'-AMP-Activated Protein Kinase Catalytic Subunit Alpha-1. NCI

Thesaurus. Code C116033.

5'-AMP-activated protein kinase catalytic subunit alpha-1 (559 aa, $64 \mathrm{kDa}$ ) is encoded by the human PRKAA1 gene. This protein is involved in the phosphorylation of metabolic enzymes, transcription regulatory proteins and microtubule-associated protein tau. 